\title{
Medical anthropology as an antidote for ethnocentrism in Jesus research? Putting the illness-disease distinction into perspective
}

\begin{abstract}
Author:
Pieter F. Craffert ${ }^{1}$

Affiliation:

${ }^{1}$ Department of New

Testament and Early

Christian Studies,

University of South Africa,

South Africa

Correspondence to:

Pieter Craffert

email:

craffpf@unisa.ac.za

Postal address:

Department of New

Testament and Early

Christian Studies, PO Box

392, Unisa 0003, South Africa

Dates:

Received: 22 Oct. 2010

Accepted: 02 Feb. 2011

Published: 07 June 2011

How to cite this article:

Craffert, P.F., 2011,

'Medical anthropology

as an antidote for

ethnocentrism in Jesus

research? Putting the

illness-disease distinction

into perspective', HTS

Teologiese Studies/

Theological Studies 67(1),

Art. \#970, 14 pages. DOI:

$10.4102 /$ hts.v67i1.970
\end{abstract}

(C) 2011. The Authors Licensee: OpenJournals Publishing. This work is licensed under the Creative Commons Attribution License.
Medicine often has side-effects or unintended consequences that are more harmful than the original disease. Medical anthropology in general and the illness-disease distinction in particular has been introduced into historical Jesus research with the intent to protect it from medicocentrism and thus to offer ways of comprehending sickness and healing in the world of Jesus and his first followers without distorting these phenomena by imposing the biomedical framework onto the texts. In particular the illness-disease distinction is used for making sense of healing accounts whilst claiming to cross the cultural gap. Based on an analysis of the illness-disease distinction in medical anthropology and its use in historical Jesus research this article suggests that instead of protecting from ethnocentrism this distinction actually increases the risk of ethnocentrism and consequently distorts in many instances the healing accounts of the New Testament.

\section{Introduction}

It is remarkable how frequently medical anthropology in general and the illness-disease distinction in particular are nowadays invoked in New Testament scholarship to facilitate ethnocentric-free cross-cultural interpretation. John Pilch suggests that insights from medical anthropology in general and the illness-disease distinction in particular will facilitate 'crosscultural communication, understanding, and interpretation' (2000b:130). He maintains that concepts such as illness and disease, healing and curing 'have eliminated or at least minimized the risk of falling into medicocentric interpretations' (2010:147). John Dominic Crossan (1994:80) argues that insights from cross-cultural anthropology, such as the 'basic distinction' between illness and disease in medical anthropology, 'prevent us from projecting some current American presuppositions back into the ancient Mediterranean world'. For Eric Eve (2002:353), Kleinman's 'careful distinction' between illness and disease is devised for cross-cultural comparison and may be applicable to the ancient Mediterranean and therefore also to the gospel accounts. Richard Horsley claims that reductionist psychological explanations can be avoided when stories about demon possession are interpreted by means of critical medical anthropological categories. In particular the illness-disease distinction gives him the license to treat cases of demon possession as instances of political-economic exploitation whilst exorcisms are seen as events of opposition to imperial rule (see 2008b:43). In his words, 'critical medical anthropologists have recognized that illness often involves particular relationships of power, domination, and deprivation' (2008a:85).

If these insights were true, they would provide powerful interpretive tools for understanding Jesus' healings as historical acts whilst ethnocentric misinterpretation would be avoided. However, the truth is that taxonomic schemes, however necessary and indispensable for research, can also be the source of error and obfuscation when dealing with nature, history or reality. The first step in determining whether these claims are valid would be to ask how the distinction functions in medical anthropology and whether it in fact is a proper tool for cross-cultural interpretation.

\section{Medical anthropology and the illness-disease distinction}

In the English language, the terms illness and disease are synonymous and often difficult to distinguish from sickness. However, in both medical and medical anthropological circles a distinction is often made: physicians treat (and cure) diseases and patients experience (and are healed from) illnesses.

Within the biomedical paradigm ${ }^{1}$ a conceptual distinction emerged between symptoms and signs. Symptoms are 'subjective feelings reported by the patient' whilst signs are 'objective indications

1.The hallmark of the biomedical paradigm is the disease model that developed over time from organ pathology to cellular and more recently molecular pathology. It holds that a disease is completely scientifically understood 'when its molecular and genetic basis has been defined' (Kriel 2002:115). Disease is thus 'a material entity and can be completely described in physicalist language' (Kriel 1997:184). 
of disease detectable by the physician' (Evans 2003:31). This is clearly illustrated by Howard Spiro from the Yale Medical School who remarks:

As a biomedical physician, I like to discriminate between the disease, which is what the physician or the imaging technologies can detect, and the illness, what the patient feels. For me, as a gastroenterologist, disease is the stomach ulcer; dyspepsia, its pain, is the illness.

(in Harrington 1997:211; see also Helman 1981:551)

However, for at least two related reasons the application of this distinction to cross-cultural settings is problematic.

\section{The fluidity of terms}

The first reason is that the definition of both terms illness and disease is rather fluid. This can be illustrated by looking at the term disease which is complex and imprecise in many respects. For one, it is not always easy to identify something as a disease. Spiro remarks that the distinction between disease and illness is rather 'fuzzy' (1997:45) and illustrates it by asking whether hypertension is a disease or an illness. What about cancer and high cholesterol (see 1997:46)? In chronic disorders such as diabetes, ischemic heart disease or asthma it is difficult to distinguish the disease form the illness (see Kleinman 1980:74). Furthermore, it is widely acknowledged that sickness can occur in the absence of disease (see, e.g. Kleinman 1980:74) whilst someone can have a disease (such as, asymptomatic hypertension or HIV infection) without being sick (see Eisenberg 1977:11; Helman 1981:551).

The view of disease as merely physical, biological or related to viruses, bacteria and the like does not even hold up within the biomedical paradigm. In fact, within the biomedical circles of the World Health Organization (WHO) the term disease is today used for a broad spectrum of sicknesses, the majority of which is probably sociogenic (see, e.g. Winkelman 2009:39). ${ }^{2}$ Even within the world of biomedicine few would think of disease as purely organic or biological. Disease, the medical anthropologist Merril Singer remarks, 'must be understood as being as much a social as a biological product' (1990:182).

Hence, it should be kept in mind that the term disease is nowadays used (in a narrow sense) to describe sicknesses that have organic or physical causes or to describe (in a wider sense) any organic and physical manifestation of sickness (immaterial whether the cause is infectious or social). It should be noted that Murdock uses the term illness synonymous with this broad definition of disease as 'any impairment of health serious enough to arouse concern,

2.Communicable or infectious diseases in humans are the result of a host of biological agents, such as, viruses, bacteria, fungi and parasites. Typically the infectious diseases are categorised into two major types, acute and chronic. In contrast to communicable diseases (infections), the World Health Organization states that chronic or noncommunicable diseases are by far the leading cause of mortality in the world today representing $60 \%$ of all deaths (see WHO n.d. (a):1). The cluster of the world tunicale and mental diseases covers a whole range (a) .1). The cluster of nonditions, conditions, such as, heart disease, stroke, cancer, chronic respiratory diseases and diabetes and the five main culprits are all lifestyle related: raised blood pressure, raised cholester n.d.(b):1). Of the ten selected causes of death by the WHO, the three highest (cerebrovascular diseases, ischaemic heart diseases and cancer) belong to the category of chronic or noncommunicable diseases. whether it be due to communicable disease, psychosomatic disturbance, organic failure, aggressive assault, or alleged accident or supernatural interference' $(1980: 6) .^{3}$ In this definition the term, illness equals that of disease as covering the whole spectrum of sicknesses.

It should by now be apparent that both terms have more than one meaning (definition) which defies the notion of an illness-disease distinction. But there is a second reason that demonstrates this even more forcefully.

\section{What medical anthropologists do, why they do it and how they do it}

The second reason why the application of the illness-disease distinction to cross-cultural settings is not obvious is to be found in what medical anthropologists do, why they do it and how they do it. Therefore, as background to an understanding of the illness-disease distinction, three observations about medical anthropology will briefly be presented.

\section{Medical anthropology exists by virtue of biomedicine}

Medical anthropologists are anthropologists who since the end of World War II work primarily in the field of medicine and health care. Therefore, Singer notes that the 'job description' of medical anthropology, is 'a service sector for biomedicine' (1990:179; see also Inhorn 2010:268). Most medical anthropologists are socialised in biomedicine and struggle with cross-cultural interpretation because of the differences between biomedicine and the variety of health care systems they encounter. Lock and Scheper-Hughes (1990:49) point out that one of the biggest challenges for medical anthropology is 'to come to terms with biomedicine'. The paradox is that the cross-cultural gap exists precisely because of the dominance (and contribution) of biomedicine, and the challenge is not whether biomedicine will be included in a cross-cultural interpretive process but how to account for it. Or, as Rhodes says: 'Western biomedicine and medical anthropology are intimately connected. Many medical anthropologists work in biomedical settings or study problems that have been defined in biomedical terms' (1990:159). ${ }^{4}$

Although it was not until the 1960s that the term medical anthropology was used and appreciated in anthropological circles (see Foster 1978:3), its roots go back to interest in physical anthropology, ${ }^{5}$ ethnomedicine, culture and 3. He explicitly does not use the illness-disease distinction in any of the definitions below: "I shall speak consistently of theories of illness rather than disease, since the word "disease" has too narrow a connotation, suggesting primarily the communicable virus-borne or bacteria-borne ailments. "Illness" serves far bette to connote the wider range of phenomena which we are interested in' (Murdock 1980:6). As can be seen in the explanation here, the term illness for him covers the whole spectrum of sickness since his concern is with the variety of explanatory models that health care systems provide in order to categorise sickness.

4.Although medical anthropologists 'seek to compare medical systems across cultural boundaries without bias for or against any one perspective, they themselves are often rooted in the perspective of Biomedicine' (Hahn 1995:3). Or as Rhodes (1990:159) points out, medical anthropologists 'are members of societies in which biomedicine provides the dominant forms of explanation and treatment for illness and are thus participants in as well as observers of the culture of biomedicine'.

5.Physical anthropologists are by definition medical anthropologists and have for decades been interested in comparative human biology and the impact of nutrition on growth as well as the correlation between body build and diseases or the on growth as well as the correlation between body build and diseases or the
distribution of disease amongst human populations. Most of them come from the distribution of disease amongst human populations
field of medical anatomy (see Foster 1978:4-5). 
personality studies ${ }^{6}$ and international public health. ${ }^{7}$ The only branch that actually concerns itself with the understanding of non-Western medical systems is ethnomedicine. The antecedents of ethnomedicine are to be found in the work of the pioneer anthropologists who looked at all aspects of traditional life, including sickness and health care. When examining the fruits of medical anthropology, one way is to distinguish between theoretical, ${ }^{8}$ clinically applied medical anthropology and critical medical anthropology. Much research in medical anthropology is conducted in conjunction with medical and health care personnel and fits into international public health programmes (see Foster 1978:8-9; Rhodes 1990:159). Critical medical anthropology, however, understands health issues 'in light of the larger political and economic forces that pattern interpersonal relationships, shape social behavior, generate social meanings, and condition collective experience' (Singer 1990:181; see Rhodes 1990:159). Critical medical anthropology has contributed to insights about the causes of and conditions for sickness that go far beyond the reductionistic view of the 'germ theory' found in the biomedical paradigm. The important point to note is that medical anthropology exists by virtue of the biomedical paradigm and is not a way of bypassing it.

\section{Medical anthropology is no safeguard against ethnocentrism}

Given their proximity to biomedicine, and, like all other anthropologists their involvement in cross-cultural interpretation, medical anthropologists are not immune to the infections from ethnocentrism. ${ }^{9}$ In fact, medical anthropology as such is no safeguard against ethnocentrism, since, as the medical anthropologist Robert Hahn points out, the socialisation of anthropologists in biomedicine 'has led to two visions within the field of medical anthropology as a whole, sometimes to double vision within single practitioners' (1995:3)..$^{10}$

The first ethnocentric vision, called medicocentrism, ${ }^{11}$ follows when the superiority or universality of biomedicine is taken for granted in cross-cultural interpretation and results in

6.Between the 1930s and 1950s there emerged interest, especially in psychiatric circles, in the sociocultural influences on personality and particularly the understanding of human behaviour (such as, arctic hysteria or running amok) in particular contexts.

7.Subsequent to WW II the extension of Western programmes of 'development' to the rest of the world included the distribution of clinical medicine and most of medical anthropology emerged in this interaction between local and biomedical health care systems (see Foster 1978:7-8). Therefore, the majority of medical anthropologists are employed in these circles and this constitutes the main arena for the development of medical anthropology as an academic discipline.

8.Since sickness and health care are just as much part of cultural systems as politics, economics or religion, medical anthropologists also concerned themselves with theoretical reflection about the cross-cultural interpretation of these aspects (see Foster 1978:8)

9.The ethnocentric coin is double-sided: 'If the first $\sin$ of the social scientist is the belief that the practices of his own people are superior to all, the second $\sin$ is the failure to distinguish genuine differences among people' (Wax \& Wax 1962:180). Although anthropologists by training have a belief structure opposed to ethnocentrism, it is not easy to avoid it.

10.Elsewhere this is referred to as the difference between 'universalists' and 'cultural relativists'; the former position 'emphasizes cross-cultural similarities' whilst the latter 'contends that cultures should be understood in their own terms with an appreciation of context and arbitrariness' (Ward 1989:27).

11.The success of Western science and related factors, Fabrega points out, "have produced a form of ethnocentrism, with biomedical diseases seen as the only real ones' (1975:974, n. 2) - a position labelled 'medicocentrism' (Pfifferling 1981:197) where all sickness is filtered through the lens of biomedicine.
Medicocentrism

Biomedical (folk) health care system - Traditional (folk) health care system

Xenocentrism

FIGURE 1: Two visions in medical anthropology.

alien sickness and healing episodes being dressed up in biomedical garments. As Foster (1976:773) himself a medical anthropologist complains, more often than not it happens that 'anthropologists filter the data of all exotic systems through the lens of belief and practice of the people they know best'; and if that system is biomedicine the result is medicocentrism (for a detailed discussion of this, see Rhodes 1990).

The second ethnocentric vision in medical anthropology is called xenocentrism:

In the second vision, common in analyses of non-Western medical systems, researchers have professed to reveal the local medical 'reality' in its own terms; in their concern not to impose their own vision on those they study, these researchers have assumed that the local, indigenous explanations of the world of sickness and healing are valid. [The xenocentric vision assumes] that the cultures of others have exclusive access to the truth - at least in their home setting.

(Hahn 1995:3)

By repeating the concepts, assumptions or descriptions of an alien health care system in a biomedical context is not to avoid ethnocentrism ${ }^{12}$ but to avoid cross-cultural interpretation. In other words, in cross-cultural interpretation ethnocentrism is avoided neither by imposing the biomedical paradigm (e.g. DSM-IV) nor by adopting the native's point of view or the local explanation of phenomena (e.g. a so-called culturebound syndrome). In both instances a linear comparison between health care systems results in the truth of one system being imposed onto another - xenocentrism is just the flip side of medicocentrism but equally ethnocentric (see Figure 1 for a schematic representation).

The (ethnocentric) shortcoming of both visions can be illustrated by means of the two sides of the same coin (Figure 1). On the one side is the question whether or not concepts from the DSM-IV or the ICD-10 ${ }^{13}$ can be used across cultural

12.The latter referred to as emic constructs often suffer ethnocentrism in being trapped in the native's point of view that does not allow proper cross-cultural interpretation. The others' (emic) perspective can be taken as superior to or be imposed onto the own (etic) perspective without avoiding ethnocentrism. The categorisation by the anthropologist James Lett of emic and etic interpretive constructs will be followed in this study: 'Very simply, emic refers to the native's point of view; etic refers to the scientist's viewpoint. Emic constructs are descriptions and analyses conducted in terms of the conceptual schemes and categories considered meaningful by the participants in the events or situation being analysed. Etic constructs are descriptions and analyses conducted in terms of being analysed. Etic constructs are descriptions and analyses conducted in terms of the conceptual schemes and categories considered meaningful by the community of scientific observers' (Lett 1987:62, see also the application of this model to
cross-cultural psychological research in Berry 1969:123).

13.DSM-IV is the Diagnostic and Statistical Manual of Mental Disorders - Fourth Edition and ICD-10 refers to the International Statistical Classification of Diseases and Related Health Problems - Tenth Revision. 
boundaries. ${ }^{14}$ On the other side is the question whether there really are conditions (so-called culture-bound syndromes) that are incomparable to those in other cultures.

Whilst the very term culture-bound syndrome ${ }^{15}$ presupposes that some sicknesses are culture-free or culture-blind, it can always be asked whether a certain condition in one culture is not similar to that in another. Secondly, as insights from the multifaceted position of sickness show, humans are not only constrained by culture but also by biology, mind, society and environment. Thirdly, the comparative view shows that local explanations neither exhaust phenomena nor describe them exclusively. The truth of the matter is that cross-cultural interpretation cannot take place without shared concepts. If we are trapped in our frameworks research across cultures is impossible. ${ }^{16}$

\section{Analytical models for cross-cultural interpretation can pretend to be ethnocentric-free}

The third and last observation is that only analytical models for cross-cultural interpretation can pretend to be ethnocentric-free. The hallmark of a scientific or analytical model, Engel (1980:543) points out, 'is that it provides a framework within which the scientific method may be applied' for analysis and comparison. In order to be used for analytical and comparative interpretation of phenomena across cultural boundaries, the scientific method needs a theoretical place to stand: 'Observation and understanding are built from categories, hypotheses, and principles of knowledge ... one could not begin the reconstruction of knowledge without a conceptual platform' (Hahn 1995:3). ${ }^{17}$ Or, in the warning of Berry: 'Without some established framework for making cross-cultural comparisons, I can only foresee an accumulating hodge-podge of unrelated anecdotal studies' (1969:127).

The structure of an analytical model can be illustrated by means of the African cooking-pot model. The analogy of the three legs of the African cooking pot suggests that between the emic logic of the culture itself and the etic logic of the dominant Western biomedical paradigm there is 'the actual incidence, qualitative and quantitative, of disease' (Worsley

14.Is the application of these manuals to cultures outside of the biomedical paradigm always and necessarily ethnocentric (or medicocentric)? This seems to be the position of cultural relativists who deny any psychic unity for humankind and are appalled when such categories are used to describe local phenomena - such as, trance like state for amok in Indonesia (Krippner 1997b:347).

15.More than one definition of culture-bound syndromes exists. One of the understandings of the term is that it refers exclusively to conditions found in one culture only (see Hahn 1995:45); the best example would be kayak angst which culture only (see Hahn 1995:45); the best example would be kayak angst which
can by definition only occur amongst the 'Eskimos' (see Hughes 1985:17). Another can by definition only occur amongst the 'Eskimos' (see Hughes 1985:17). Another by disease agents (see Hahn 1995:46-47). The latter replicates the nature-culture dichotomy: some sicknesses are bodily or physical, thus diseases, whilst others are mental and consequently illnesses (see Hughes 1985:10; Hahn 1995:47-48). This definition probably dominates in New Testament scholarship.

16.Erica Bourguignon points out that a general category is preferable to creating new disorders for each cultural instance (see 1992:332). Therefore, despite her DSM-IV, she applies precisely those categories in mapping such phenomen trance in DSM-IV, she applies precisely those categories in mapping such phenomena across cultures (see 1968). And despite his claim for cultural relativism, dissociation is and locations (see 1997a:6 and cf., Bourguignon 2005:378).

17.For another view on the critical debate within medical anthropology (see, e.g. Singer [1990])

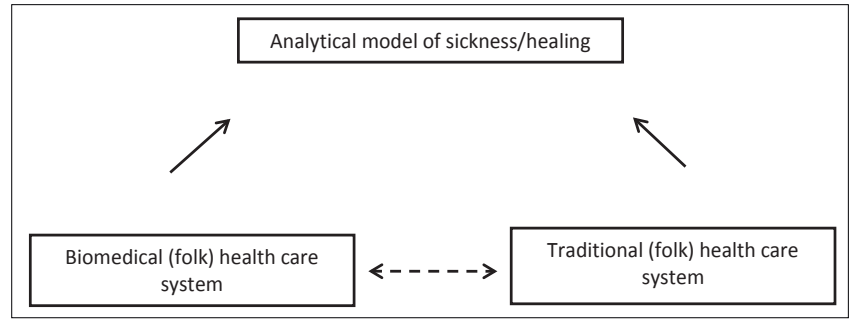

FIGURE 2: The African cooking-pot model of analysis.

1982:328). And the body of scientific knowledge about sickness and healing is much more extensive than that contained by any particular ethnomedical model or health care system, biomedical or otherwise. Instead of a comparison (or clash) between two opposing health care systems (the biomedical and a local paradigm) the interpretive problem can be presented as a three-way process in which the analytical model of the interpreter serves as fixed point of comparison.

This suggestion is based on at least two theoretical principles.

The first is that analytical models are different from operational folk or local health care models. A scientific or analytical model itself is not a health care system (it does not operate as a local health care system within a particular culture). Therefore, an analytical model is not the basis of any dogma, medical or otherwise, and consequently, there is a huge difference between practitioners of any health care system and cross-cultural interpreters trying to make sense of a variety of health care systems. Unlike actual health care models, scientific models are modified and discarded if they are no longer useful.

Secondly, a model of reality is not reality itself and this is particularly true of local health care systems. Consequently, as suggested by Hahn (see 1984:14, 18, 19), a distinction should be made between a model and what it models, an account of phenomena and what is accounted for. Health care systems, be it the biomedical or any other health care system, are partial models of the human experience of sickness and not the totality of sickness. Although all health care models are rational (and the biomedical model is based on science), none is in itself an analytical or scientific tool. Despite the worldwide dominance of biomedicine since the previous century (see Hahn 1995:131), the biomedical model remains a culture specific folk model of sickness and healing (see Fabrega 1975; Hahn 1995:15) and is in itself not a scientific model. Whilst all health care systems with various degrees of success highlight particular features of sickness, none captures it in totality. The body of knowledge about sickness is far more extensive than that of any one system's presentation.

\section{Intercultural models for cross-cultural interpretation}

Scholars concerned with ethnocentrism (medicocentrism or xenocentrism) in either biomedicine or medical anthropology are promoting intercultural models (the third leg of the tripod) for the cross-cultural interpretation of sickness and 


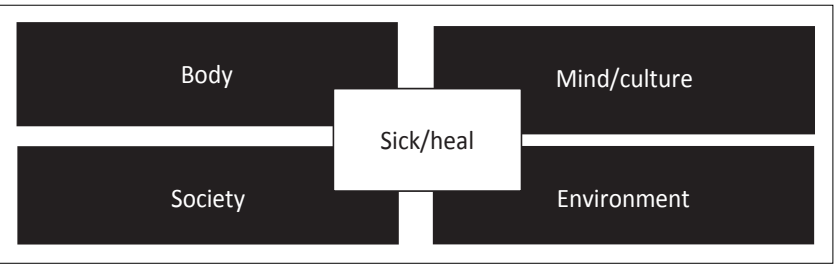

FIGURE 3: An intercultural model of sickness and healing.

healing. Such models contain ideal typical descriptions of sickness and healing that are multifaceted because they refer to the body, mind, society and environment as contributing factors in sickness and healing. The hallmark of such models is that they do not go back beyond the 19th century germ theory of disease but are not trapped there because all of them see health and illness as interlocking processes that are determined by biological and environmental, as well as psychological factors' (Fabrega 1971:389). DSM-IV and ICD10 categories are not excluded but used together with other conceptual tools in describing particular sickness conditions. In simple terms, an intercultural model of sickness and healing acknowledges the wide spectrum of sickness aetiologies whilst realising that the experience of sickness is multifaceted.

Intercultural models view all sickness and healing phenomena as complex bio, psycho, social and environmental interactions. When used for cross-cultural interpretation such models begin, though not necessarily end, with the indigenous and personal understanding of patients (whether they are from a traditional or biomedical framework), and when interpreting a particular sickness or syndrome, the local understanding or experience of it is seen as necessary but not sufficient for its full description (see Hahn 1995:54-55). ${ }^{18}$ The primary insight of one such model, known as the biopsychosocial model (see Engel 1977, 1980) is the multifaceted aetiology of most sickness conditions and the insight that effective healing consists of an integrative biopsychosocial intervention or process. $^{19}$

The implication of such a cross-cultural model is that all sicknesses, today or in the past, whether acknowledged by the culture or local health care system or not, are multifaceted entities. This interpretive framework suggests that the comparison of health care systems can take place via an engagement with what is modelled by each system whilst avoiding the ethnocentrism of imposing any one health care system onto the others. Put differently, the local understanding and description of each and every instance of sickness and healing is compared to the multifaceted model of sickness and healing provided by the analytical model.

Comparing the biomedical health care system (paradigm) to such a framework will show that most sickness conditions

18.Such models take 'each alternative, informant framework seriously enough to encompass its understandings, while not taking each framework (including our own) so seriously as to exclude other possibilities' (Hahn 1984:19).

19.Other contenders are the biocultural (Morris 1997:200) or the integrative (Weiner \& Fawzy 1989) models. are medicalised with the search for a technical solution to all problems ${ }^{20}$ whilst the actual instance of sickness is multifaceted. Similarly, a comparison of some traditional health care systems will show their failure to recognise organic, physiological or material factors in sickness and the need for medical intervention in many instances of sickness.

\section{Medical anthropology and the ambiguity of the illness-disease distinction}

If it is true that medical anthropologists have different visions on cross-cultural interpretation, one should not expect a unified view on the illness-disease distinction. Before looking at the different definitions of illness, it is necessary to re-emphasise that this distinction is an affirmation of and not a transcending of the biomedical paradigm. Fully aware of its roots in the Western biomedical paradigm, the biomedical distinction between sign and symptom is echoed in the description of medical anthropologists Kleinman, Eisenberg and Good (1978) when they say that the illness-disease distinction:

holds that diseasein the Western medical paradigm is malfunctioning or maladaptation of biologic and psychophysiological processes in the individual; whereas illness represents personal, interpersonal, and cultural reactions to disease and discomfort.

(Kleinman, Eisenberg \& Good 1978:252 [Author's emphasis])

This is an adoption of Eisenberg definition: 'patients suffer "illnesses"; physicians diagnose and treat "disease" (1977:11). If anything, this is an affirmation that the distinction is a product of the biomedical paradigm and not a tool to facilitate cross-cultural interpretation between biomedical and other health care systems - a point to be confirmed by the following analysis. The analysis will furthermore show that the illness-disease distinction in medical anthropology is much more complex and problematic than assumed by this definition.

\section{Illness as the response or cultural reaction to disease}

The often quoted distinction by Kleinman (1980) echoes the aforementioned definition of illness as dependent on disease:

Disease refers to a malfunctioning of biological and/or psychological processes, while the term illness refers to the psychological experience and meaning of perceived disease. Illness includes secondary personal and social responses to a primary malfunctioning (disease) in the individual's physiological or psychological status.

(Kleinman 1980:72)

In this formulation the illness-disease distinction is not only a replication of the symptom-sign distinction in biomedicine but also displays the medicocentric vision of biomedicine. According to this understanding, illness is dependent on disease since illness is defined in terms of disease, ${ }^{21}$ the two express different interpretations 'of a single clinical reality'.

20.The success of Western medicine with certain classes of disease problems 'breeds the ideological error that a technical fix is the potential solution to all' (Eisenberg 1977:14). The medicalisation of health has misled biomedicine in affering pill or medical intervention for each and every malady.

21.At some point Kleinman (1980:74) suggests that illness in the absence of disease could be considered 'abuses of the medical sick role'. 


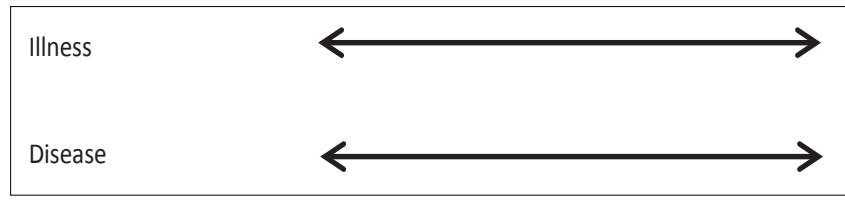

FIGURE 4: Illness dependent on disease.

In this definition, Kleinman insists, illness and disease are not entities but 'explanatory concepts' (1980:73). Schematically it can be presented in Figure 4.

Within this understanding disease is universalised (when people are sick they suffer from some kind of a disease) whilst patients' experiences (their reactions) are localised as illnesses.

\section{Illness as an independent entity from disease}

In what can be called the independent definition, the understanding of illness is not dependent on disease. To once more quote Kleinman, Eisenberg and Good (1978):

physicians diagnose and treat disease (abnormalities in the structure and function of body organs and systems) whereas patients suffer illnesses (experiences of disvalued changes in states of being and in social function; the human experience of sickness). ${ }^{22}$

(Kleinman, Eisenberg \& Good 1978:251)

About this definition Eisenberg says (1977:11): 'Illness and disease, so defined, do not stand in a one-to-one relationship'. In other words, illness is not dependent on disease. ${ }^{23}$ In this understanding there are illnesses that exist independently from disease and are no response to any disease. ${ }^{24}$ Schematically it can be presented in Figure 5.

In an attempt to give expression to Kleinman's application of the double vision, the medical anthropologist Allan Young suggests a schema where there are illnesses without disease counterparts and vice versa (see 1982:266). Schematically this position can be presented in Figure 6 .

But you cannot have your cake and eat it! Illness cannot both be a response to disease and represent independent entities. Whilst realising this dilemma, Young altered the definition of illness to 'a person's perceptions and experiences of certain socially disvalued states, but not limited to, disease'

$\longleftrightarrow$ Illness

FIGURE 5: Illness independent from disease.

22.This is a replication of Eisenberg's definition: 'illnesses are experiences of disvalued changes in states of being and in social function; disease, in the scientific paradigm of modern medicine, are abnormalities in the structure and function of body organs and systems' (1977:11).

23.Illness 'can accompany an injury, infection, or imbalance, or even exist without them' (Krippner \& Achterberg 2000:360).

24.Disease without illness refers to acute disorders, like massive trauma, acute intoxication or an infection where there is little or no time for the disease to be shaped into an illness experience (see Kleinman 1980:74).

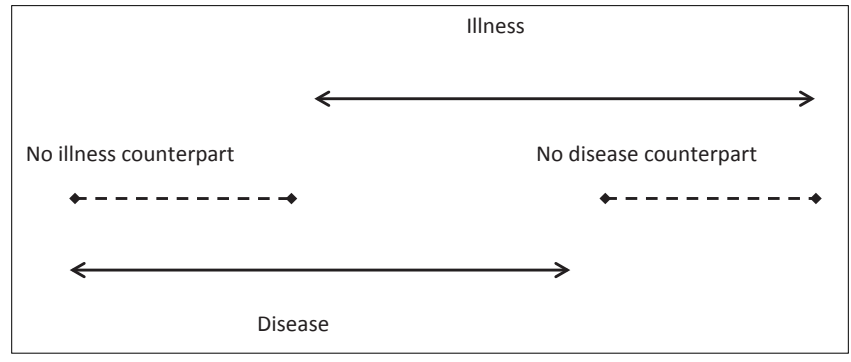

FIGURE 6: A partial overlap between illness and disease.

(1982:265). However, the term illness cannot be used both for the response to disease and for independent sicknesses (or disvalued states) next to disease. And the attempt to avoid some of these problems by insisting that neither illness nor disease are entities, but concepts (see Fabrega 1971:390; Kleinman et al. 1978:252; Pfifferling 1981:210) is unsuccessful because once it is admitted that disease is not a thing - only a concept - there is no thing of which illness can merely be the subjective cultural experience (see Eisenberg 1977:18).

\section{IIIness as a label for traditional health care systems}

It is a small step from the notion of illness as entity independent from disease to the idea that the sicknesses experienced and described by traditional health care systems are merely illnesses. When the terms illness and disease are used to describe entire health care systems, the natureculture dichotomy often kicks in, in order to label traditional health care systems as merely concerned with illness whilst it is maintained that traditional healers can only heal illnesses. The root of this notion is visible in the following description:

Medical anthropologic studies show that traditional healing in developing societies and popular health care in our own are principally concerned with illness, that is, with treating the human experience of sickness. Healers seek to provide a meaningful explanation for illness and to respond to the personal, family, and community issues surrounding illness.

(Kleinman et al. 1978:252) ${ }^{25}$

Even if it were the case that people in traditional societies experience sickness similar to popular conceptions of patients in Western societies (and one can understand the comparison), it does not mean that they are not suffering from potential diseases. The fallacy of this dichotomy between, on the one hand, the biomedical and, on the other hand, popular notions of sickness in Western societies and local understandings in traditional societies, is to equate the local description (or experience) with the totality of the sickness. Even if a sickness is experienced as an illness, this does not mean someone is not suffering from an identifiable disease.

Besides the fact that this distinction presupposes the biomedical paradigm ${ }^{26}$ (see Hahn 1984:19 in this regard), it

25.It should be noted that medical anthropologists often operate within clinical settings that are defined by the presence of biomedicine. Their concern, therefore, is to find ways of doing jut the pro the folk explanation of patients who hapere, is to find ways of doing justice to the folk explanation of patients who happens to come from an alien or different cultural setting and health care system.

26.'By using it [the illness-disease distinction] to separate natural facts from cultural constructions, medical anthropology runs the risk of taking on characteristics of biomedicine itself' (Rhodes 1990:166). 


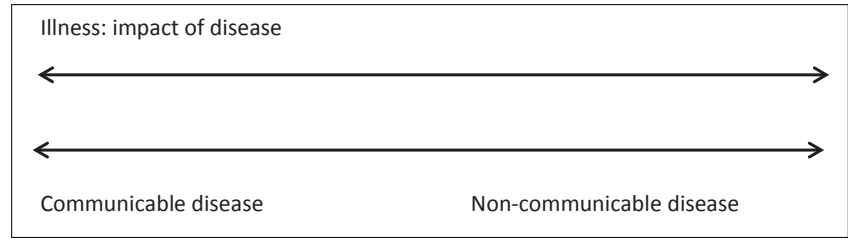

FIGURE 7: Illness as the impact of disease.

reverts back to the dichotomous notion of sickness as either physical (real) or mental (not real) whereas the best theories today take into account the multifaceted nature (physical, individual, social, etc.) of sickness. In many instances, and this is one of them, the illness-disease distinction is a variant of the mind-body and the culture-nature dichotomies (see Lock et al. 1990:53; Rhodes 1990:166). As illustrated earlier, this easily happens in the case of so-called culture-bound syndromes where an outdated definition of disease as bodily (natural) entity informs such dichotomies.

\section{Illness as the effect or impact of disease}

In yet another formulation the definition of illness is extended to include the effect of sickness symptoms on patients. Medical anthropology, Kleinman (1986b) says:

has advanced a technical distinction between 'illness' and 'disease' with illness defined as socially learned and culturally shared ways of perceiving, labelling, experiencing, and reacting to symptoms. This includes most notably the personal and interpersonal problems illness creates or intensifies.

(Kleinman 1986b:230 [Author's emphasis])

This definition of illness covers the personal and cultural response as well as the labelling of diseases, but, it also includes the personal and social impact of sickness.

Schematically this position can be presented in Figure 7.

This understanding of the illness-disease distinction is no tool for cross-cultural differentiation because irrespective of the kind of disease someone suffers from, within all cultural settings people will experience some effect or impact of sickness. And needless to say that illness thus defined has no cross-cultural currency - it merely is a label for the individual impact or effect of disease, whether infectious or noncommunicable. Even though the impact will be mediated by or be dependent on culture it does not in any way facilitate cross-cultural interpretation.

\section{IIIness as the patient's understanding of sickness}

For the sake of being comprehensive it should be noted that Hahn - who rejects both ethnocentric (linear) visions of anthropology but sees cross-cultural interpretation in terms of the tripod analytical model - suggests that together with disorder, the terms illness and disease can be used to refer to different ideologies (perspectives) of sickness. He suggests that the same suffering or sickness experience can be viewed from any of three ideological positions but primacy is given to illness ideology. The illness perspective is the patient's understanding of suffering and should be given priority in any diagnosis, be it as the starting point for

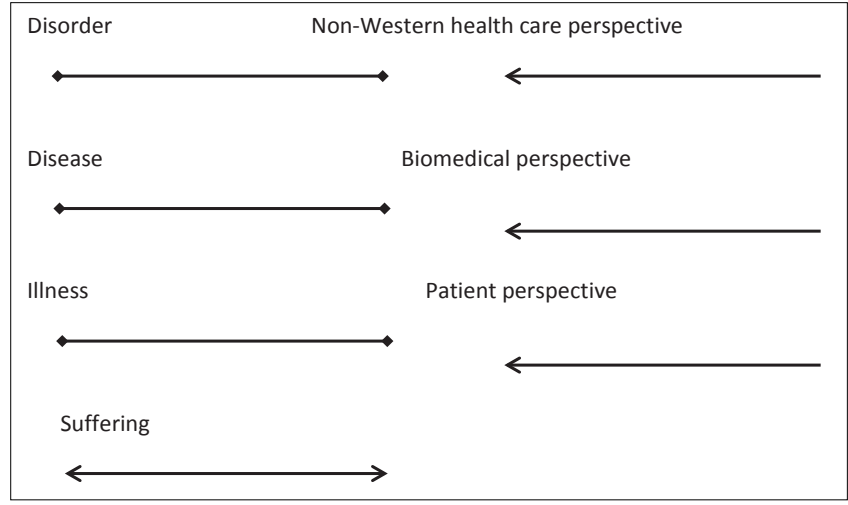

FIGURE 8: Illness, disease and disorder as different expressions of suffering.

comprehending the sickness only. When the same suffering episode is described from the perspective of biomedicine, he calls it a disease ideology whilst the perspective from varied traditional healers (non-Western health care system) is referred to as a disorder ideology (see 1984:15-16).

Because biomedicine is 'the dominant folk model of disease in the Western world' (Engel 1977:130), the illness experience of Western people will tend to simulate the disease ideology whereas the suffering of people from other health care systems (their illness) will simulate their own folk understanding. Therefore, any suffering (or disease in the broad sense of communicable or non-communicable diseases) can be experienced as different illnesses depending on the person's local health care system.

Schematically this position can be presented in Figure 8 .

The logic of this proposal can be illustrated by means of HIV and AIDS. For Western people the sickness or suffering will be experienced as an infectious disease whilst for most African people today it is experienced as an illness resulting from witchcraft (see Ashforth \& Nattrass 2005:289; Dickinson 2008:283). Neither of these affirms or denies anything about the impact or effect of the illness on the individual or his or her community but departs from the dominant aetiology explanation of different local health care systems.

\section{Summary remarks on the illness-disease distinction in medical anthropology}

The illness-disease distinction in medical anthropology indeed contributes to sensitise biomedical practitioners as well as social scientists to the multifaceted aetiology of sickness and the complex nature of sickness experiences (see Lock et al. 1990:53). It provides the basis for studying the influence of cultural factors (beliefs, issues of meaning and cultural experiences) and context (social, economical and political conditions) on the construction and experience of sickness (see Rhodes 1990:165). However, it is not unproblematic in medical anthropological circles.

First of all, there is not $a$ or the definition of illness and disease and the semantic status of both terms is by no means 


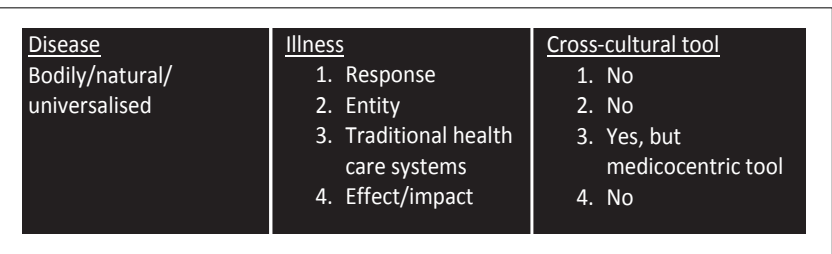

FIGURE 9: A summary of the illness definitions.

unequivocal and in many respects the source of confusion because of covert forms of ethnocentrism. The paradox is that in some instances the notion of disease is relativised to the Western medical paradigm with illness belonging to 'the other' and in other cases disease is universalised and given primacy - something to which illness is only a secondary and culturally variable reaction (see Hahn 1984:10). The preceding analysis supports the finding of Hahn (1984:1), who after reviewing some of the major works on the illnessdisease distinction in medical anthropology, concludes that this distinction 'has been made inconsistently from work to work, and even within works' - and these differences largely correlate with the different anthropological visions.

Secondly, medical anthropology as such is not a tool for cross-cultural interpretation and does not automatically protect from ethnocentrism. On the contrary, by design it often invokes either medicocentrism or xenocentrism. Much of medical anthropology itself suffers from medicocentrism and/or xenocentrism because of the linear comparison of health care systems - the question is which health care system is privileged in the comparison. To say it once more, medical anthropology as such is no safeguard against ethnocentrism but the site of its struggle and the above discussion bears that out. Consequently, the illness-disease distinction is not simply a tool for cross-cultural interpretation but was designed within the clinical setting dominated by the biomedical paradigm in order to account for the cultural gap. Disease and illness are terms that describe the same sickness phenomenon from different perspectives and neither is a tool to distinguish different kinds of sicknesses nor a way of discriminating between various health care systems. The illness-disease distinction does not avoid the biomedical paradigm but in practice assumes biomedicine.

Thirdly, whilst little has been said about the medicocentric definition of disease that is assumed in this distinction, it remains remarkable that of the four definitions of illness and disease, only one pair functions as a cross-cultural tool.

Neither as response to disease nor as independent entity nor seen as the impact of sickness can illness be taken as a tool to understand ethnomedical descriptions of sickness in a biomedical world. Ironically, it is only in the third definition where illness is used to label traditional health care systems that it functions in a medicocentric way as a tool for crosscultural interpretation. ${ }^{27}$ The ethnocentric labelling of all traditional health care systems as merely concerned with illness is hardly an improvement on traditional medicocentrism.

27.From the perspective of cross-cultural interpretation of sickness during field work in Zambia, Frankenberg remarks about the 'highly characteristic inadequacies' of Kleinman's model that is marked by a 'cultural and curative bias' (Frankenberg 1980:199)
Once the biomedical definition of disease is eroded from its ethnocentric position, it becomes apparent that all sicknesses are biopsychosocial phenomena, some with and others without identifiable infectious disease aetiologies. Whatever the actual aetiology of a sickness, it can be individually, socially and culturally experienced in unique ways. In view of these considerations, universalising the disease model is not only ethnocentric (a case of medicocentrism) but irresponsible, because no justice is done to the complexity of human sickness conditions.

Fourthly, when no clear distinction is made between reality and models of reality, accounts of phenomena are identified (or confused) with the phenomena accounted for. This happens when sickness constructions of health care systems are taken as the sickness. When applying the scientific vision, such as the biopsychosocial model of sickness, it is much easier to see that each local health care model provides an understanding of complex biopsychosocial phenomena, albeit some in very reductionist ways. This point can be illustrated by means of the HIV and AIDS pandemic. A large percentage of people in southern Africa infected with the HIvirus claim that they are 'bewitched' or are sick because of the Devil. The belief of bewitchment does not mean they are not HIV positive. What it does say is that the same sickness condition can be described by means of various explanatory models, but how to cross the cultural gap between them is another matter.

\section{The illness-disease distinction in New Testament scholarship}

Within the social-scientific project it is undoubtedly rhetorically powerful to claim that the illness-disease distinction is a 'basic distinction' in medical anthropology (or as Crossan does, in echoing the words of Kleinman, to call it a 'key axiom' in medical anthropology). In addition to the fact that there is no such fundamental distinction and that it functions within particular anthropological visions only, an analysis of the illness-disease distinction in New Testament scholarship will reveal a rather disconcerting picture. It appears that New Testament scholars seem oblivious to the fact that the terms illness and disease are used in medical anthropology with a variety of meanings, and that the distinction is not a tool for cross-cultural interpretation. Consequently, they invent a different spectrum of meanings for the terms and instead of avoiding medicocentrism this distinction functions to promote ethnocentric understandings of Jesus' healings within disguised theological or ideological agendas. These are strong claims that need to be substantiated.

\section{The variety of definitions of illness and disease in New Testament scholarship}

From reading New Testament scholarship on the illnessdisease distinction one will not know that there is no $a$ or the definition of the terms in medical anthropology. In fact, New Testament scholars are either oblivious of the fact that the terms have a variety of meanings in medical anthropology and the biomedical paradigm or they deliberately conceal 
them in service of another agenda. This is apparent from the way the distinction is presented.

When Eve calls on Kleinman's 'careful distinction'28 in order to present illness as the impact or effect of sickness, it is done at the expense of all the other definitions that Kleinman also promotes. ${ }^{29}$ This represents not only a limited understanding of the terms but a deliberate exclusion of those definitions that would undermine his argument.

But it is in the mixing of meanings under the pretension that there is $a$ or the single set of definitions of the terms illness and disease that the distortion can best be seen. Although it starts with Pilch, it is in the work of John Dominic Crossan who follows Pilch religiously ${ }^{30}$ that the creative (distorted) exegesis of these terms can be illustrated.

In his book on the historical Jesus, Crossan ascribes the illness-disease distinction to George Peter Murdock (see Crossan 1991:319) and then claims that Arthur Kleinman distinguishes 'as Murdock above' between illness and disease with illness seen as the psychosocial and cultural response to disease (see 1991:336). Three years later Leon Eisenberg and Kleinman are presented as the champions of medical anthropology 'or comparative ethnomedicine' [author's emphasis] who in Crossan's (1994:80) words propose 'a basic distinction' between illness and disease. However, Crossan starts with the dependent definition of illness (as a response to disease) but with a sleight of hand combines it with the medicocentric view which sees all traditional health care systems as merely concerned with illness. For this we have to return to the tradition history of the terms as employed by him, starting with Murdock and following his presentation to Eisenberg and Kleinman.

It is simply a misrepresentation of Murdock to link his name to this illness-disease distinction because, as shown earlier, he uses the term illness synonymous with sickness as referring to all kinds of diseases. However, Crossan's use of Eisenberg and Kleinman is even more disconcerting. The definition of Eisenberg used by Crossan is the independent one and in Eisenberg's article is followed by the following words: 'Illness and disease, so defined, do not stand in a oneto-one relationship' (1977:11) - in other words, it is not merely

28.On the contrary, Kleinman himself is responsible for mixing the illness-disease distinction with different visions of medical anthropology. Several years after introducing the illness-disease distinction, Kleinman (1986a:38) refers to it as 'stillincompletely worked out theoretical distinction in medical anthropology. The anthropological visions in this debate started with Kleinman.

29.For Eve (2002:353), also claiming the authority of Kleinman's dependent definition, illness can be seen as the 'sociocultural construction placed on a sickness ... Whereas disease affects only the afflicted individuals, illness may affect many other people besides'. The same understanding of illness and disease is proposed by Donald Capps (2008:xvii) who suggests that illness can be seen as the personal, interpersonal, and social consequences of disease from their organic symptoms'. In other words, whilst maintaining that disease covers all sickness, due to either organic or contextual factors, this position defines illness as the impact that sickness has on an individual or person. Lung cancer (a non-communicable disease) will have the effect of incapacitating a patient whilst HIV infection (a disease) will have the effect of incapacitating a patient whilst HIV infection (a patient depending on cultural setting.

30.On the dust cover of Pilch's book Crossan is quoted as saying: 'Everything I know about healing in the New Testament I learned form John Pilch'. This is confirmed by the very same distinction that forms the basis of their analyses: the illness-disease distinction. a response to disease. Crossan not only omits these words, but without any reference to the latter pages replaces them in the same quotation with words from a paragraph three pages down (in a different argument) that suggests that indigenous healers can only treat illnesses. Illness is thus presented as if Eisenberg suggests that it is a legitimate (medicocentric) label for traditional health care systems. On the very next page Crossan's second authority for the illness-disease distinction is Kleinman's dependent definition of illness as the response to disease (see Crossan 1994:81).

By combining Murdock's definition of illness as umbrella term for all sicknesses with Eisenberg definition of illness as an independent entity together with Kleinman's notion of illness as merely a response to disease, Crossan comes up with a mixed bag that assigns the features of the dependent definition to the others. Therefore, in his view, 'the leper who met Jesus had both a disease (say, psoriasis) and an illness, the personal and social stigma of uncleanness, isolation, and rejection' (1994:82). Furthermore, the features of the dependent definition that people always assign meaning to sickness (construct illnesses) are then transferred to traditional health care systems with the claim that folk healers always successfully heal illnesses.

Jumping between definitions, however, started with Pilch (as will be illustrated at a later stage). Here the focus is on the claim promoted by him that healing always takes place but that curing is rare. Besides the fact that features of one meaning of illness are transferred to the other, common sense tells us that neither one of these claims is true. If curing was rare, most people alive today would be sick because most of us have at some point suffered from an infectious disease (such as the common flu). But the truth is that many (if not most) infectious and congenital diseases are today very effectively cured by medical treatment. ${ }^{31}$ It is the sociogenic diseases that are hard to deal with and, like today, many people in Jesus' day must have suffered bodily sicknesses that were not caused by germs.The fact that people always assign meaning to sickness (assign symptoms to their sickness signs) does not mean healing automatically takes place.

Furthermore, the notion that people always find meaning in sickness (which, might or might not be the case in reality) cannot support either of the historical claims that Jesus probably healed (or potentially could heal) what is called mere responses to diseases (illness). And even if patients always and infallibly experience meaning in sickness, it does not follow that healers automatically have an effect on sicknesses that are not caused by viruses, bacteria and the like (whether they are called culture-bound syndromes or sociogenic diseases and psychogenic diseases). Local explanations cannot remove or replace the sickness reality caused by infectious diseases.

31.This is just one example: 'As a clinical haematologist, I witnessed and lived through a period of enormous change in the treatment and prognosis of people with conditions such as leukaemias and lymphomas. Many of the patients I cared for had diseases, which at the outset of my career were rapidly fatal, but where scientific advances meant that several of these illnesses became amendable scientific advances meant that several of these illnesses became amendable
to treatment. Thus, patients who developed these diseases in later times often to treatment. Thus, patients
survived' (Dawson 2008:xv). 
Perhaps more remarkable (and disturbing) is the fact that no New Testament scholar after Pilch and Crossan whilst quoting the very same sources, has either picked these discrepancies up or even noted the variety of definitions within medical anthropology. It should be of great concern for the socialscientific project in New Testament interpretation if social science and anthropological material is used in such an uncritical and proof texting way. Raiding these disciplines for 'insights' (like fundamentalists raid biblical texts for proof) cannot advance responsible interdisciplinary research. But there is more to the confusion of these 'insights' in New Testament scholarship, because not only are these studies used in an uncritical way, they are used so in different ways. It should be noted that whilst citing the same medical anthropologists (often even the same words) New Testament scholars come up with distinct definitions of their own for illness and disease.

\section{Illness and disease as tools for cross-cultural interpretation?}

The primary function of the illness-disease distinction in New Testament scholarship is to serve as a tool for cross-cultural interpretation of Jesus' healing stories. But it is precisely in these attempts that the new ethnocentrism is revealed and theological or ideological agendas are promoted. I will start with the viewpoint of Crossan.

Crossan's position is captured in the often repeated example of the film Philadelphia (1993) where the main character is suffering from HIV and AIDS, and whilst the disease could not be cured, his illness was healed (see 1994:81, 1998:294, 2009:128). Applied to the blind, the lame or the deaf encountered in the gospel stories, Crossan maintains that they were suffering from some kind of common disease that Jesus could do nothing about whereas their illnesses he could heal. $^{32}$

By this Crossan is providing a powerful historical explanation as to what the historical Jesus was doing during the socalled healing miracles. At least for the healing stories that he considers authentic, people were suffering from specific diseases (sickness conditions which can be attributed to specific biological or organic defects and can only be treated by medical practitioners) that Jesus could not cure and therefore, he only offered therapeutic comfort - he 'healed' them, seeing that illness as the response to disease can easily and effectively be healed by a folk healer. In his words: 'for disease you are better off with the doctor and the dispensary, but for illness you are better off with the shaman and the shrine' (1991:336). ${ }^{33}$ Here the nested assumption is that the

2.In his words: 'I presume that Jesus, who did not and could not cure that disease [leprosy] or any other one, healed the poor man's illness by refusing to accept the disease's ritual uncleanness and social ostracization.... By healing the illness without curing the disease, Jesus acted as an alternative boundary keeper in a way subversive to the established procedures of his society' (Crossan 1994:82).

33.In several other studies he defends this position by stating that medical anthropologists and cross-cultural studies of indigenous healing make a distinction between curing disease and healing illness (see, e.g., 1994:80-81, 1998:294) and therefore, Jesus' healings were merely 'ideological, symbolic, and material resistance to oppression and exploitation. Such resistance cannot directly cure disease, as vaccines can destroy viruses or drugs can destroy bacteria, but cure disease, as vaccines can destroy viruses or drugs can destroy bacteria, but
resistance can heal both sickness and illness and thus sometimes indirectly cure disease' (1998:331). patients were suffering from diseases that were experienced as illnesses and the latter can effectively be healed by a folk healer. This assumption derives from the mixing of definitions (as shown earlier). Whilst Pilch apparently also promotes this position, analysis shows that his tool kit contains a different set of meanings.

It is not without reason that I started with Crossan, because it is much more difficult to make sense of Pilch's arguments. ${ }^{34}$ He departs from the definition of illness and disease as formulated by Kleinman ${ }^{35}$ (see Pilch 2000a:13, 25, 59-60, 93, 2008:98) and, similar to Crossan, illustrates it with a contemporary (and very personal) example of a patient (his late wife) suffering from ovarian cancer. Although she was not cured, despite the best available chemotherapy she was $100 \%$ healed because healing, the restoration of meaning to life, Pilch says 'occurs always' (2000a:141). According to this understanding Jesus did not and could not cure any disease but only healed some illnesses. ${ }^{36}$ This is based on Pilch's belief that 'cure is a relatively rare occurrence in human experience' (2000a:141) and in his specific understanding of the distinction between curing and healing, 'curing is efficacious when biomedical changes take place; healing is efficacious when the people who seek it say it is' (2000a:34). Therefore, the kind of healing that Jesus was involved in, was symbolic healing in which the healer mediates culture, and when, for instance demons were exorcised, the anxious client believed the cause of the problem was gone. What took place was a transformation of the experience of the patient (see 2000a:32, 35). What Jesus did was to reintegrate people into society: 'He restored meaning to the lives of these collectivistic persons' (2000a:142). ${ }^{37}$

It is clear that in this understanding, depending on the perspective, the same human condition is either a disease (the real bodily or material defect) or an illness (the mindful experience). Again, an insight with far-reaching implications: New Testament documents were not concerned with disease but with illness, which reflects a sociocultural perspective and healing involves the provision of personal and social meaning and therefore 'all illnesses are always and infallibly healed' without the disease necessarily affected (2000a:93; and see Pilch 1991:190-192). All of this presupposes the dependent definition of illness.

It might seem as if Pilch is saying the same thing as Crossan but his position is a little more confusing, as illustrated by the example of moonstruck, the term used by Matthew (17:15 and see 4:24) to describe the condition of a boy from whom Jesus exorcised a demon. Pilch claims that it is 'irresponsible and

34.I am not the only one to find large gaps in his arguments. Eve remarks that 'Pilch's work is unfortunately vitiated by self-contradiction, misuse or misunderstanding of his sources, and a tendency to digress' (Eve 2002:351, n. 2). As an example Eve mentions the application of emic and etic to the illness-disease distinction (see 2002:354).

35.As most others who uncritically follow him in this regard, the illness-disease distinction is based on Kleinman (1980:72)

36.Elsewhere Pilch states that illness and disease are 'explanatory concepts and terms' useful in exploring different facets of a 'single reality', called sickness (1991:191).

37.As elsewhere, Pilch (2000a:159) confirms this dichotomy in the glossary on sickness where it is stated that the sickness reality can be viewed from two perspectives and described by one of two explanatory concepts, disease or illness. 
grossly unfair' (2010:153) to translate and understand it as an instance of epilepsy. This is not surprising for he says: 'Given the absence of scientific terminology in antiquity, it seems best to speak of illnesses rather than diseases in the Bible' (Pilch 2008:98). Moonstruck was an illness that should not be treated as if it were a disease in order to make it accessible to modern interpreters; moonstruck cannot be considered epilepsy but is an instance of a 'culture-bound syndrome' (Pilch 2000a:19). Here a sudden but significant change of definition occurs, as illness no longer is the response to a disease because if it were, it could well have been the cultural response to, say, epilepsy. But Pilch uses a different definition of illness and disease to argue the opposite, namely, that moonstruck was definitely not epilepsy and he gives it another twist by saying that it (the illness) should be seen as a culture-bound syndrome. This is also the case with leprosy mentioned in the Gospels which most certainly were not instances of Hansen's disease but should according to Pilch also be considered culturebound syndromes (see Pilch 2000a:54). Whatever the precise conditions, Pilch claims that they were not 'diseases' but 'illnesses' (see 2000b:131). After ruling out Hansen's disease (because no evidence for its existence in 1st century Palestine has been confirmed) it is postulated that these 'marks' on the skin of the patients were only illnesses. The reasons being that without biomedical knowledge and microscopes the ancients would not have been able to identify 'diseases' whilst their cultural interpretation of the conditions suggests these were mere illnesses (see Pilch 2000b:131). ${ }^{38}$ Similarly, it is medicocentric to consider the eye condition mentioned in Matthew 9:27-31 as the healing of a cataract (see 2008:101) whilst conditions resulting from the evil eye are also culturebound syndromes or folk-conceptualised disorders (2000a:19).

Unlike Crossan who claims that these illnesses were responses to diseases, Pilch clearly operates in the preceding arguments with illnesses as independent entities from disease. Remarkably, both claim the features of the independent definition of illness (that illnesses are always healed). In addition, they share the linear structure of crosscultural interpretation but within different anthropological visions.

\section{The impact of a linear interpretive process}

Whilst both Pilch and Crossan employ the illness-disease distinction they do so in different ways: both follow the linear logic but part ways in that one follows a xenocentric and the other the medicocentric anthropological vision. Pilch is to be credited for insisting that the New Testament healing stories cannot simply be framed in terms of biomedical categories but then falls into the xenocentric trap by insisting that the interpreter should respect the emic understanding of health and sickness (moonstruck is not epilepsy and demon possession is not multiple-personality disorder). Unfortunately, this claim merely rests on the xenocentric

38.In one instance he goes so far as to suggest that the local or emic understanding of the illness is merely an 'unclean skin condition' whilst the notion of leprosy in the texts itself (Mt 8:3) is a medicocentric (etic) interpretation (see Pilch 2010:153). I boggles the mind how a 1st century description of a sickness condition labelled by them as leprosy can be considered a biomedical description. position that takes the local understanding as the full one. The fallacious implication of this kind of reasoning is that if no laboratory is around, people cannot suffer from diseases (such as epilepsy or HIV and/or AIDS). In this view, crosscultural interpretation takes place when biomedical categories are avoided and local explanations are endorsed. But this happens at the expense of Pilch's own definition of illness as a response to disease. He transfers one of the features from this definition of illness to that of illness as an independent entity: because illness as response always takes place and results in healing (which, by the way, is not necessarily true), it does not mean that illness as independent entity (such as culture-bound syndromes) is always and infallibly healed.

Crossan on the other hand, assumes that people were sick because they were suffering from diseases (such as leprosy as a skin condition) that were experienced as illnesses and a folk healer such as Jesus could only heal the illnesses and do nothing about the diseases. This is medicocentrism in its authentic garment where the ideas of biomedicine are universalised and applied to all other cultural settings whilst relegating traditional healers to therapists of illnesses.

Claiming that 1st century Mediterranean people only experienced illnesses although diseases were around (see Pilch 2008:98) is as reductionistic (and misleading) as saying that they were really sick but satisfied with healing. Donald Capps (2008:xvii), in my view, is correct in saying about this view of Jesus' healings: 'The miracle is in the fact that the illness was healed without the disease being cured' (and see the criticism of Avalos 1999:26). At the very least the dichotomy between healing and curing as crosscultural tool is a distortion and misrepresentation of medical anthropological research. If and when that distinction is made, it is important to ask what it is made for. For example, Kleinman himself is aware of the complexity of the healing process; cultural healing, he says, is only part of the healing process because the healing process usually involves two related activities - the provision of effective control of the disease and of personal and social meaning of the experience of illness' (1986a:35). ${ }^{39}$

But these dichotomies are precisely the result of the linear way of conducting cross-cultural interpretation. Not only is the illness-disease distinction suffering from a random mixing of features from the different definitions, it also remains trapped in the ethnocentric visions of cross-cultural interpretation. The solution, in my view, is not a refinement of either of these visions but the development of an intercultural model that operates in a different way (the African cooking-pot model).

\section{Healing illnesses as acts of political resistance}

If the preceding claims are true that New Testament scholars pay no attention to the diversity of definitions in medical anthropology and randomly pick and choose meanings or

39.Within medical anthropology the issue of the efficacy of different therapies is a huge issue and something often debated but not in simplistic dualistic terms of healing versus curing (see, e.g. Eisenberg 1977:14; Hahn 1995:32-38). 
definitions, the question remains as to why this happens. To what end is the illness-disease distinction employed in New Testament scholarship? I want to suggest a theological motif that functions in opposition to traditional theological and scholarly claims that Jesus' healings should be seen as miraculous cures.

The employment of medical anthropology in general and the illness-disease distinction in particular is an attempt to avoid the medicocentrism of the position which maintains that the patients encountered by Jesus were suffering from serious diseases, and because Jesus was no medical practitioner, healing them must have resulted from miraculous deeds (see Craffert 2008:254-255 for examples of this approach). Whilst the texts' claims that Jesus healed successfully are taken at face value, other explanations must be offered for this success and nothing is more useful than the concocted picture of illnesses. Either in the garment of culture-bound syndromes or as mere reactions to diseases, the healing of illnesses became the scapegoat to carry the successful deeds of the historical Jesus. Yes, Jesus healed, the implicit argument goes, either mere illnesses or culture-bound syndromes that can easily be treated by a folk healer. But there must be something more to these healings as, apparently, it is not enough to claim that the historical Jesus healed such conditions. Compared to a Jesus who performed miraculous deeds this is unimpressive and therefore an additional explanation is offered as to what Jesus was doing in healing illnesses. This is where modern political ideology comes into the picture: in the healings Jesus actually performed deeds of political resistance if not treason. And again, illness is the vehicle or scapegoat to carry the burden. Two examples will suffice.

Since, as the texts claim, Jesus successfully healed people and because they only suffered from illnesses and not diseases, there seems to be an urge to ascribe some powerful meaning to these acts. This is what is happening in Pilch's most recent suggestion that Jesus' healings could be seen as 'treasonous political behavior' (2010:154).

Based on the distinction that illnesses are not diseases, ${ }^{40}$ they were not the physical problem. The state of pollution or loss of meaning was, and therefore, healing only addressed and restored the latter. For this argument Pilch relies on the work of Moerman and suggests that the 'meaning response' is the process by means of which healing was mediated by Jesus (see Pilch 2010:147). The provision of meaning is based on power and authority and Jesus acted as distributor of meaning and in that way he could be a successful healer. The problem was that he occupied no recognised position of power or authority and that infuriated the authorities: 'Since authorities did not authorize this use of power, Jesus was given the death penalty for his treasonous activity' (Pilch 2010:154).

In this argument illness is no longer the assignment of meaning to disease, but Jesus is the one providing meaning,

40.Leprosy or an 'unclean skin condition', for example, is not 'a biomedical problem but rather a sociocultural problem', Pilch (2010:153) says. and since meaning is the means of healing illness, Jesus' healings of illnesses are taken as secure facts. It is unfortunate that, based merely on the occurrence of the term meaning in the dependent definition of illness (as the provision of meaning to disease) and in the term meaning response, that this connection is made. The meaning response ${ }^{41}$ (placebo effect) as the effect of any therapy on the body based on perceived meaning by a patient has absolutely nothing to do with the experience of sickness. Put the other way round, whether sickness is experienced as meaningful (an illness) or not and whether someone is suffering from any kind of disease experienced as an illness is totally unrelated to the meaning response. The latter refers to the fact that therapeutic actions are perceived as meaningful and thus impact on a patient. In fact, the meaning response is the most common denominator researchers in biomedicine are trying to eliminate in the testing of medications. If Jesus as folk healer activated a meaning response (therapeutic process) it has nothing to do with whether people experienced their sickness meaningfully or not and is no indication that they only suffered from illnesses.

For Horsley Jesus' exorcisms, in particular the Beelzebul pericope, can be understood as a political act and more precisely as a form of political resistance and symbolic defeat of Roman rule. Based on the illness-disease distinction he suggests that illness 'often involves particular relationships of power, domination, and deprivation' (2008a:85). Consequently, he treats the accounts of demon possession as mere illnesses and Jesus' exorcisms as defeat of Roman rule (see 2003:102-109). As illnesses (which were not diseases) he argues that these stories were told and were heard by 1st century Mediterranean audiences as (symbolic) defeats of Roman Imperial power.

If the endorsement or dismissal of these accounts as miracles and magic constitute a reductionism as claimed by Horsley (see 2008a:85), then presenting them merely as symbolic acts of political resistance is a reduction, if not misrepresentation, of a different kind. Biopsychosocial sickness episodes are reduced to illness accounts brought on by Roman imperialism (see 2003:109) whilst the complexity of such human experiences is neglected. There is no doubt about the relationship between spirit possession as the congenital psychological mechanism of dissociation and sociocultural, economic or political circumstances (see, e.g. Bourguignon 2005). But this does not mean that all instances of spirit or demon possession can be reduced to such circumstances because as Bourguignon (see 2005:376) shows, instances of non-trance possession are a major explanatory theory for the presence of disease in many settings. Demon possession

41.The work of Daniel Moerman (another medical anthropologists) that cannot be placed in the healing-curing (or nature versus culture, mind versus body) dichotomy, shows that 'meaning can activate biological processes' (2002.151). The intervention of any therapist, by means of active medication and drugs or The intervention of any therapist, by means of active medication and drugs or simply by providing meaning, can have an impact on several bodily processes and this in part explains why traditional healers are successful in many respects. Few anthropologists today will claim that traditional or folk healers do not actually heal and/or cure some diseases (see, e.g. Kleinman \& Sung 1979). Even amongs anthropologist it is no secret that biomedicine is by far the most successfu medicine for certain categories (notably communicable or infectious and congenital diseases) of sickness (see, e.g. Eisenberg 1977:14) 
can simply be the local explanation for disease (such as bewitchment functions for many as explanation for HIV or AIDS) and the illness-disease distinction as such is no justification for such a claim about the nature of the condition.

\section{Conclusion}

This article started with the observation that in some circles Jesus research is dramatically influenced by the employment of medical anthropology in general and the illness-disease distinction in particular. Claims are made that medicocentrism is avoided whilst cultural sensitive readings provide cross-cultural interpretation and understanding of the healing accounts in the gospels. In view of the above discussion it should be asked whether any of these claims are true and whether as a taxonomic scheme, the illnessdisease distinction obscures or facilitates cross-cultural interpretation.

Pilch is to be credited for creating an awareness of both the cross-cultural comparative tasks and the potential of medical anthropology for dealing with the healing accounts in the gospels. Unfortunately, his own application as well as that of his closest followers suffer from a selective poaching of 'insights' or concepts from medical anthropology without really engaging in cross-cultural interpretation. It is difficult to escape the suspicion that the illness-disease distinction functions in Jesus research to serve a theological or ideological agenda. Whilst it is in many circles no longer fashionable to say that Jesus' healings were extraordinary miracles, it is theologically convenient to uphold their historicity by classifying them as healings of illnesses. Perhaps the biggest challenge for New Testament scholars who want to move into interdisciplinary and cross-cultural interpretation is to move away from simplistic and one-dimensional explanations and to come to grips with the complexity of the relationships between culture, body and society. Ultimately, moonstruck, bewitchment and the explanation of a virus are only ethnomedical labels for conditions that are by nature complex biopsychosocial phenomena. If it cannot be said that bewitchment excludes the diagnosis of HIV and AIDS, does moonstruck exclude epilepsy? From this perspective it is easy to see that moonstruck is a culture-bound explanation for something that could (or could not) have been epilepsy (an issue that cannot a priori be settled by the illness-disease distinction).

Although he is not a New Testament scholar, Capps applies biomedical insights in his cross-cultural interpretation of Jesus' healings in another medicocentric way but one that suggests the importance of a scientific model for doing cross-cultural interpretation. He suggests that most of the conditions mentioned in the New Testament could be taken as somatoform disorders as defined by the DSM-IV (see 2008:3-14). These are conditions with physical, organic symptoms caused by psychosocial factors and are not treated as pure 'medical' conditions. It is an empirical question whether the category of somatoform disorder is used by him to shape or illuminate the data. ${ }^{42}$ The eternal predicament of anthropological psychology is characterised by the oscillation between assuming a psychic unity of humankind (universally applicable nosology) and a cultural relativism of psychological functioning (a diversity of mental disease, varying from culture to culture). Analytical models of sickness aim at mediating between these two because they treat both sickness and healing as complex configurations of biopsychosocial phenomena.

\section{Acknowledgement}

I offer this article as a tribute to Prof. Andries van Aarde who has worked relentlessly to introduce and encourage the use of the social sciences and the social-scientific perspective in South African New Testament scholarship.

\section{References}

Ashforth, A. \& Nattrass, N., 2005, "Ambiguities of "culture" and the antiretroviral rollout in South Africa', Social Dynamics 31(2), 285-303. doi: $10.1080 / 02533950508628716$

Avalos, H., 1999, Health care and the rise of Christianity, Hendrickson, Massachusetts, $\mathrm{MA}$

Berry, J.W., 1969, 'On cross-cultural comparability', International Journal of Psychology 4(2), 119-128. doi: 10.1080/00207596908247261

Bourguignon, E., 1968, 'World distribution and patterns of possession states', in R. Prince (ed.), Trance and possession states, pp. 3-34, Burke Memorial Society, Montreal. doi: 10.1177/136346159202900406

Bourguignon, E., 1992, 'The DSM-IV and cultural diversity', Transcultural Psychiatric Research Review 29, 64-114. doi: 10.1002/9780470996409.ch21

Bourguignon, E., 2005, 'Spirit possession', in C. Casey \& R.B. Adgerton (eds.), A companion to Psychological Anthropology: Modernity and psychocultural change, pp. 374-388, Blackwell, Oxford. doi: 10.1002/9780470996409.ch21

Capps, D., 2008, Jesus the village psychiatrist, Westminster John Knox, Louisville, KY/ London.

Craffert, P.F., 2008, The life of a Galilean shaman: Jesus of Nazareth in anthropologicalhistorical perspective, Cascade, Eugene, OR.

Crook, Z.A., 2009, 'Review of Capps, D Jesus the village psychiatrist', Biblical Theological Bulletin 39(1), 48-49. doi: 10.1177/01461079090390010604

Crossan, J.D., 1991, The historical Jesus: The life of a Mediterranean Jewish peasant, Harper, San Francisco, CA.

Crossan, J.D., 1994, Jesus: A revolutionary biography, Harper, San Francisco, CA.

Crossan, J.D., 1998, The birth of Christianity: Discovering what happened in the years immediately after the execution of Jesus, HarperSanFrancisco, San Francisco, CA.

Crossan, J.D., 2009, 'Jesus and the challenge of collaborative eschatology', in J.K. Beilby \& P.R. Eddy (eds.), The historical Jesus: Five views, pp. 105-152, IVP Academic, Downers Grove, IL.

Dawson, A., 2008, Healing, weakness and power: Perspectives on healing in the writings of Mark, Luke and Paul, Paternoster, Milton Keynes/Colorado Springs, $\mathrm{CO} /$ Hyderabad.

Dickinson, D., 2008, 'Traditional healers, HIV/AIDS and company programmes in South Africa', African Journal of AIDS Research 7(3), 281-291. doi: 10.2989/ AJAR.2008.7.3.5.652

Eisenberg, L., 1977, 'Disease and illness: Distinctions between professional and popular ideas of sickness', Culture, Medicine and Psychiatry 1, 9-23. doi: 10.1007/ BF00114808

Engel, G.L., 1977, 'The need for a new medical model: A challenge for biomedicine', Science 196(4286), 129-136. doi: 10.1126/science.847460

Engel, G.L., 1980, 'The clinical application of the biopsychosocial model', American Journal of Psychiatry 137(5), 535-544.

Evans, D., 2003, Placebo: Mind over matter in modern medicine, HarperCollins, London.

Eve, E., 2002, The Jewish context of Jesus' miracles, Sheffield academic Press, Sheffield.

Fabrega, H. (Jr.), 1971, 'The study of medical problems in preliterate settings', Yale Journal of Biology and Medicine 43, 385-407.

Fabrega, H. (Jr.), 1975, 'The need for an ethnomedical science', Science 189, 969-975 doi: $10.1126 /$ science. 1220008

Foster, G.M., 1976, 'Disease etiologies in non-Western medical systems', American Anthropologist 78, 773-782. doi: 10.1525/aa.1976.78.4.02a00030

42.The racist assumptions in some of his examples aside (see Crook 2009:49; Klancher 2009:200), Capps succeeds in bringing these stories down to the level of natural phenomena and in seeing somatoform disorders as real sickness conditions. 
Foster, G.M., 1978, 'The new field of medical anthropology', in G.M. Forster \& B.G. Anderson (eds.) Medical anthropology, pp. 1-10, John Wiley \& Sons, New York.

Frankenberg, R., 1980, 'Medical anthropology and development: a theoretical perspective', Social Science \& Medicine 14B, 197-207.

Hahn, R.A., 1984, 'Rethinking "illness" and "disease"', Contributions to Asian Studies 18, 1-23.

Hahn, R.A., 1995, Sickness and healing: An anthropological perspective, Yale University Press, New Haven, CT/London.

Harrington, A. (ed.), 1997, 'Placebo: Conversations at the disciplinary borders', in A Harrington (ed.), The placebo affect: An interdisciplinary exploration, pp. 208-248, Harrington (ed.), The placebo affect: An interd
Harvard University Press, Cambridge, MA.

Helman, C.G., 1981, 'Disease versus illness in general practice', Journal of the Roya College of General Practitioners 31, 548-552.

Horsley, R.A., 2003, Jesus and empire: The Kingdom of God and the new world disorder, Fortress, Minneapolis, MN.

Horsley, R.A., 2008a, 'Jesus and Empire', in R.A. Horsley (ed.), In the shadow of Empire reclaiming the Bible as a history of faithful resistance, pp. 75-96, Westminste John Knox, Louisville, KY/London.

Horsley, R.A., 2008b, “"My name is Legion”: Spirit possession and exorcism in Roman Palestine', in F. Flannery, C. Shantz \& R.A. Werline (eds.), Experientia, volume 1 . Inquiry into religious experience in Early Judaism and Christianity, pp. 41-57, Society of Biblical Literature, Atlanta, GA.

Hughes, C.C., 1985, 'Culture-bound or construct-bound? The syndromes and DSM-III', in R.C. Simons \& C.C. Hughes (eds.), The culture-bound syndromes: Folk illnesses of psychiatric and anthropological interest, pp. 3-24, Reidel, Dordrecht.

Inhorn, M.C., 2010, 'Medical anthropology at the intersections: celebrating 50 years of interdisciplinarity', Medical Anthropology Quarterly 24(2), 263-269. doi: of interdisciplinarity', Medical Ant
$10.1111 / \mathrm{j} .1548-1387.2010 .01100 . x$

Klancher, N., 2009, 'Review of Capps, D Jesus the village psychiatrist', Journal for the Study of the Historical Jesus 7, 199-200. doi: 10.1163/174551909X447392

Kleinman, A., Eisenberg, L. \& Good, B., 1978, 'Culture, illness, and care: Clinical lessons from anthropologic and cross-cultural research', Annals of Internal Medicine 88 , 251-258

Kleinman, A. \& Sung, L.H. (eds.), 1979, 'Why do indigenous practitioners successfully heal?' Social Science and Medicine 130, 7-26.

Kleinman, A., 1980, Patients and healers in the context of culture: An exploration of the borderland between Anthropology, medicine, and psychiatry, University of California Press, Berkeley, CA/Los Angeles, CA/London.

Kleinman, A., 1986a, 'Concepts and a model for the comparison of medical systems as cultural systems', in C. Currer \& M. Stacey (eds.), Concepts of health, illness and disease: A comparative perspective, pp. 29-47, Berg, New York.

Kleinman, A., 1986b, 'Some uses and misuses of the social sciences in medicine', in D.W. Fiske \& R.A. Shweder (eds.), Metatheory in social science: Pluralisms and subjectivities, pp. 222-245, University of Chicago Press, Chicago, IL/London.

Kriel, J.R., 1997, 'Transforming medicine's clinical method: A critical assessment of the influence of the natural science world-view on medicine', Scriptura 61(2), 179-192.

Kriel, J.R. 2002, 'Patients, pills and positivism: Transforming positivistic science', in C.W. du Toit (ed.), Brain, mind and soul: Unifying the human self, pp. 99-134 Unisa, Pretoria.

Krippner, S. \& Achterberg, J., 2000, 'Anomalous healing experiences', in E. Cardeña, S.J. Lynn \& S. Krippner (eds.), Varieties of anomalous experience: Examining the scientific evidence, pp. 353-395, American Psychological Association, Washington, DC. doi: 10.1037/10371-011

Krippner, S., 1997a, 'Dissociation in many times and places', in S. Krippner \& S.M. Powers (eds.), Broken images, broken selves: Dissociative narratives in clinical practice, pp. 3-40, Brunner/Mazel, Washington, DC.
Krippner, S., 1997b, 'The varieties of dissociative experiences', in S. Krippner \& S.M. Powers (eds.), Broken images, broken selves: Dissociative narratives in clinical powers (eds.), , Broken images, 361 , Brunner/Mazel, Washington, DC.

Lett, J., 1987, The human enterprise: A critical introduction to anthropological theory, Westview Press, Boulder, CO.

Lock, M. \& Scheper-Hughes, N., 1990, 'A critical-interpretive approach in medical anthropology: Rituals and routines of discipline and dissent', in T.M. Johnson \& C.F. Sargent (eds.), Medical anthropology: Contemporary theory and method, $\mathrm{pp}$. 47-72, Praeger, New York.

Moerman, D.E., 2002, Meaning, medicine and the 'placebo effect', Cambridge University Press, Cambridge.

Morris, D.B., 1997, 'Placebo, pain, and belief: A biocultural model', in A. Harrington (ed.), The placebo affect: an interdisciplinary exploration, pp. 187-207, Harvard University Press, Cambridge, MA.

Murdock, G.P., 1980, Theories of illness: A world survey, University of Pittsburgh Press, Pittsburgh, PA.

Pfifferling, J.-H., 1981, 'A cultural prescription for medicocentrism', in L. Eisenberg \& A. Kleinman (eds.), The relevance of social science for medicine, pp. 197-222, D Reidelm, Dordrecht.

Pilch, J.J., 1991, 'Sickness and healing in Luke-Acts', in J.H. Neyrey (ed.), The socia world of Luke-Acts: Models for interpretation, pp. 181-209, Hendrickson, Peabody, MA.

Pilch, J.J., 2000a, Healing in the New Testament: Insights form medical and Mediterranean anthropology, Fortress, Minneapolis, MN.

Pilch, J.J., 2000b, 'Improving Bible translation: the example of sickness and healing', Biblical Theology Bulletin 30, 129-134. doi: 10.1177/014610790003000403

Pilch, J.J., 2008, 'The usefulness of the meaning response concept for interpreting translations of healing accounts in Matthew's gospel', in D. Neufeld (ed.), The social sciences and biblical translation, pp. 97-108, SBL, Atlanta, GA.

Pilch, J.J., 2010, 'Jesus's healing activity: Political acts?' in D. Neufeld \& R.E. DeMaris (eds.), Understanding the social world of the New Testament, pp. 147-155, Routledge, London/New York.

Rhodes, L.A., 1990, 'Studying biomedicine as a cultural system', in T.M. Johnson \& C.F. Sargent (eds.), Medical anthropology: Contemporary theory and method, pp. 159-165, Praeger, New York.

Singer, M., 1990, 'Reinventing medical anthropology: toward a critical realignment', Social Science and Medicine 30(2), 179-187. doi: 10.1016/0277-9536(90)90078-7

Spiro, H., 1997, 'Clinical reflections on the placebo phenomenon', in A. Harrington (ed.), The placebo affect: An interdisciplinary exploration, pp. 37-55, Harvard University Press, Cambridge, MA.

Ward, C.A., 1989, 'The cross-cultural study of altered states of consciousness and mental health', in C. A. Ward (ed.), Altered states of consciousness and mental health: A cross-cultural perspective, pp. 15-35, Sage, London.

Wax, R. \& Wax, M., 1962, 'The magical world view', Journal for the Scientific Study of Religion 1, 179-188. doi: 10.2307/1384696

Weiner, H. \& Fawzy, I.F., 1989, 'An integrative model of health, disease, and illness', in S. Cheren (ed.), Psychosomatic medicine: Theory, physiology, and practice, vol. I, pp. 9-44, International Universities Press, Madison, WI.

WHO, n.d.(a), Chronic diseases, viewed 29 June 2009, from www.who.int/topics/ chronic_diseases/en/index.html.

WHO, n.d.(b), Surveillance of noncommunicable disease risk factors, viewed 29 June 2009, from www.who.int/mediacentre/factsheets/fs273/en/index.htm

Winkelman, M., 2009, Culture and health: Applying medical anthropology, JosseyBass, San Francisco, CA.

Worsley, P., 1982, 'Non-western medical systems', Annual Review of Anthropology 11 257-285. doi: 10.1146/annurev.an.11.100182.001531 